\title{
Role of estrogen receptor coregulators in endocrine resistant breast cancer
}

\author{
Kristin A. Altwegg ${ }^{1,2}$ (1), Ratna K. Vadlamudi ${ }^{1,2} *$ (1) \\ ${ }^{1}$ Department of Obstetrics and Gynecology, University of Texas Health San Antonio, San Antonio, TX 78229, USA \\ ${ }^{2}$ Mays Cancer Center, University of Texas Health San Antonio, San Antonio, TX 78229, USA
}

*Correspondence: Ratna K. Vadlamudi, Department of Obstetrics and Gynecology, University of Texas Health San Antonio, San Antonio, TX 78229, USA; Mays Cancer Center, University of Texas Health San Antonio, San Antonio, TX 78229, USA. vadlamudi@uthscsa.edu

Academic Editor: Simon Langdon, University of Edinburgh, UK

Received: May 27, 2021 Accepted: July 2, 2021 Published: August 30, 2021

Cite this article: Altwegg KA, Vadlamudi RK. Role of estrogen receptor coregulators in endocrine resistant breast cancer. Explor Target Antitumor Ther. 2021;2:385-400. https://doi.org/10.37349/etat.2021.00052

\begin{abstract}
Breast cancer $(\mathrm{BC})$ is the most ubiquitous cancer in women. Approximately $70-80 \%$ of $\mathrm{BC}$ diagnoses are positive for estrogen receptor (ER) alpha (ER $\alpha$ ). The steroid hormone estrogen [17 $\beta$-estradiol (E2)] plays a vital role both in the initiation and progression of BC. The E2-ER $\alpha$ mediated actions involve genomic signaling and non-genomic signaling. The specificity and magnitude of ER $\alpha$ signaling are mediated by interactions between ER $\alpha$ and several coregulator proteins called coactivators or corepressors. Alterations in the levels of coregulators are common during BC progression and they enhance ligand-dependent and ligand-independent $\mathrm{ER} \alpha$ signaling which drives $\mathrm{BC}$ growth, progression, and endocrine therapy resistance. Many ER $\alpha$ coregulator proteins function as scaffolding proteins and some have intrinsic or associated enzymatic activities, thus the targeting of coregulators for blocking BC progression is a challenging task. Emerging data from in vitro and in vivo studies suggest that targeting coregulators to inhibit $\mathrm{BC}$ progression to therapy resistance is feasible. This review explores the current state of $E R \alpha$ coregulator signaling and the utility of targeting the ER $\alpha$ coregulator axis in treating advanced BC.
\end{abstract}

\section{Keywords}

Estrogen receptor, coregulators, transcriptional activation, estrogen, hormonal action, signal transduction, endocrine therapy resistance

\section{Introduction}

Globally, breast cancer (BC) is the leading cause of cancer-related mortality in females and thus accounts for approximately 684,996 deaths annually [1]. BC is a complex and highly heterogeneous disease and is composed of distinct subtypes associated with different clinical outcomes [2]. These subtypes are based on the expression of estrogen receptor (ER) alpha (ER $\alpha$ ), the progesterone receptor (PR), and the human epidermal growth factor receptor-2 (HER2)/neu. Molecular analysis through gene expression profiling of tumors revealed four intrinsic BC subtypes: luminal $\mathrm{ER} \alpha$ positive (ER $\alpha+$; luminal A and luminal B), HER2 enriched, and basal-like [triple-negative BC (TNBC)] [3, 4]. TNBC lacks ER $\alpha$, PR, and HER2 [5].

(C) The Author(s) 2021. This is an Open Access article licensed under a Creative Commons Attribution 4.0 International License (https://creativecommons.org/licenses/by/4.0/), which permits unrestricted use, sharing, adaptation, distribution and reproduction in any medium or format, for any purpose, even commercially, as long as you give appropriate credit to the original author(s) and the source, provide a link to the Creative Commons license, and indicate if changes were made. 
The steroid hormone, estrogen [17 $\beta$-estradiol (E2)], plays an integral role in the development of normal breast tissue. Further, E2 can also function as a driver in the initiation and progression of BC. The majority of BC starts as hormone-dependent; approximately 70-80\% of BC diagnoses are ER $\alpha+$, and 55-65\% are PR positive ( $\mathrm{PR}+$ ) at the time of initial diagnosis [3]. Patients with HER2 overexpressing $\mathrm{BC}$ comprise approximately $15 \%$ of all BC diagnoses. TNBC accounts for approximately $15 \%$ of all BC and has a poorer prognosis [5-7]. In hormone receptor-positive BC, E2-ER $\alpha$ axis-mediated actions can involve classical genomic signaling, non-classical genomic signaling, and non-genomic signaling. Importantly, the specificity and magnitude of ER $\alpha$ signaling are mediated by interactions between ER and critical coregulators containing a nuclear receptor (NR) box motif [8]. This article will attempt to summarize emerging evidence on the role of coregulators in conjunction with $\mathrm{ER} \alpha$ signaling in $\mathrm{BC}$.

\section{ER and signaling mechanisms}

E2 mediates its biological effects using two distinct ERs, ER $\alpha$ and ER beta (ER $\beta$ ). The estrogen receptor $(E S R) 1$ gene located on chromosome 6 at q25.1 encodes the $66.2 \mathrm{kDa}$ ER $\alpha$ protein. While the ESR2 gene on chromosome 14 at q23.2 encodes the $59.2 \mathrm{kDa}$ ER $\beta$ protein [9]. The first and most well-characterized receptor, ER $\alpha$ was discovered in 1958 by Elwood Jensen, who later established that the estrogen-bound ER migrates to the nuclear compartment to stimulate transcription [10,11]. The ER $\alpha$ oncogene is the major driver of $\sim 75 \%$ of $\mathrm{BC}$, therefore, $\mathrm{ER} \alpha$ and $\mathrm{ER} \alpha$-regulated genes serve as therapeutic targets for ER $\alpha+\mathrm{BC}$. ER $\beta$ functions as an anti-proliferative, in many ways antagonizing the function of $\operatorname{ER} \alpha$ [12]. ER $\beta$ may function as a prognostic marker for tamoxifen resistance [13] and some ER $\beta$ isoforms may have oncogenic functions in $B C$ [14]. This review primarily focused and was limited to ER $\alpha$ oncogenic signaling mechanisms in BC.

The ERs belong to the family of steroid receptors and contain six functional domains labeled A-F (Figure 1). The $N$-terminal domain (A/B domains, encoded by exon 1 ) contains the activation of function (AF)1 region which is integral in transcriptional activity. The ER $\alpha$ can be phosphorylated by various kinases, and these phosphorylation events have been established as modulators of ER $\alpha$ activity [15]. The DNA binding domain ( $C$ domain, encoded by exons 2-4) contains two zinc-finger motifs. The hinge region (D domain, encoded by exon 4) contains regions for receptor dimerization and nuclear localization. The ligand-binding domain (LBD; E domain) contains the AF2 [16]. This domain participates in several activities including hormone binding, homodimerization and/or heterodimerization, formation of heat-shock protein (HSP) complexes, and transcriptional activation and repression. The $C$-terminal domain (F domain) is encoded by exons 5-8 [16].

Even though ER $\alpha$ and ER $\beta$ are structurally similar in modular nature, their LBDs differ in similarity. The DNA binding domains of ERs share 97\% similarity, while the AF1 and AF2/LBD domains only share 18\% and $67 \%$ similarity, respectively (Figure 1). The differences in the amino acid composition of the two ERs are suspected to facilitate the interactions of distinct coregulator proteins by ERs. ER $\alpha$ is the major ER subtype expressed in the mammary epithelium [17]. Further, ER $\alpha$ is implicated as the master regulator and driver of $\mathrm{BC}$ progression $[8,18]$. ER $\beta$, which was discovered in 1996, has very different if not opposite functions from $\mathrm{ER} \alpha$; thus, it is generally considered a tumor suppressor [19]. Two recent reviews by Zhou et al. [20] and Sellitto et al. [21] covered the role of ER $\beta$ in BC and TNBC, respectively. For this review, we only focused on $\mathrm{ER} \alpha$ coregulator-driven signaling in ER $\alpha$ hormone action and BC progression.

Published evidence implicates ER $\alpha$ signaling via these four mechanisms. (1) Classical-direct-ER signaling. The classical mechanism of ER $\alpha$ action involves E2 binding to ER, which induces conformational changes in the ER $\alpha$ protein structure. The ligand-bound ER $\alpha$ then forms a dimer and translocates to the nucleus where it binds to specific target genes containing palindromic estrogen response elements (EREs) [22]. (2) Non-classical-indirect-ER signaling. The non-classical mechanism of action involves ER $\alpha$ interactions with other transcription factors (TFs) within the nucleus such as activator protein 1 (Ap1), specificity protein 1 (SP1), etc. and together they activate a different specific set of target genes containing nonERE or half site-ERE containing genes [23]. Interestingly, approximately one-third of human genes which are regulated by ER $\alpha$ do not contain ERE-like sequences [24], which gives rise to the third mechanism of signaling. (3) Non-genomic-ER signaling. The non-genomic effects of E2-ER $\alpha$ occur rapidly through signaling 
cascades when ER $\alpha$ interacts with cytosolic kinases such as Src kinase, serine/theronine kinase (Akt), phosphatidylinositol 3-kinase (PI3K), etc. [25-27] and is activated through phosphorylation which gives to distinct genomic outcomes. (4) Lastly, the final mechanism of ER $\alpha$ signaling: ligand-independent ER signaling. ER phosphorylation by oncogenic kinases, or post-translational modifications or mutations of $\mathrm{ER} \alpha$ in the LDB contribute to structural changes in ER facilitating activation of ER target genes independent of E2 ligand [28-30]. This mode of signaling is predominant in pathological situations such as endocrine resistant $\mathrm{BC}$.

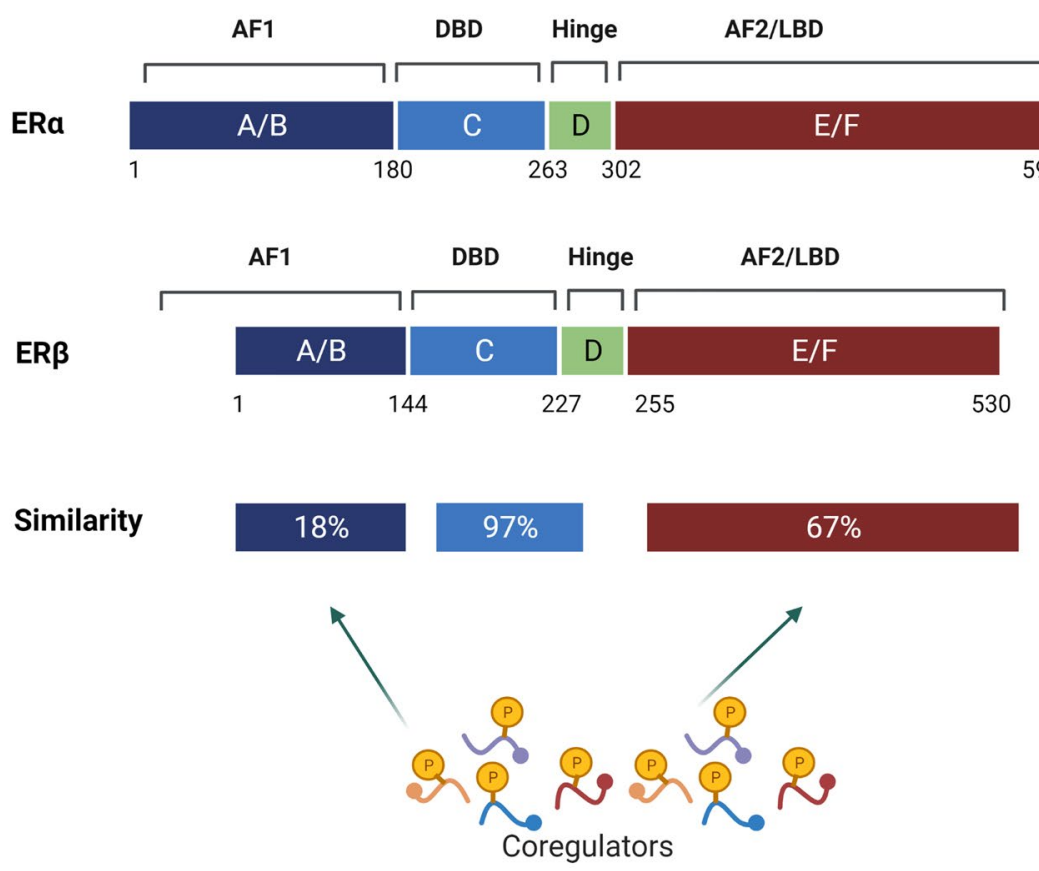

Figure 1. Schematic representation of various domains in ERa and ER 3 . ERs consist of six domains labelled $A$ through $F$. The activation of AF1 region is located in A/B-domain and the DNA binding region is located in the C-domain. The D-domain contains a flexible hinge region. The E-domain contains the ligand-dependent activation of function domain (AF2). The F domain contributes to differences in the activity of ERa and ER $\beta$ subtypes and is also involved in receptor interactions with coregulators. Chromosomal localization and similarity between various domains of ER $\alpha$ and ER $\beta$ are depicted. The AF1 and AF2 domains facilitate ligand-independent and ligand-dependent interactions with coregulators, respectively. DBD: DNA binding domain

Emerging evidence suggests that the transcriptional activity of ERs is regulated by a diverse array of coregulator proteins called coactivators and/or corepressors [8, 31] (Figure 2). Coactivators preferentially associate with $\mathrm{E} 2$ bound $\mathrm{ER} \alpha$, while corepressors associate with antagonist occupied ER $\alpha$ [32, 33]. E2 binding to ER $\alpha$ promotes the formation of multiprotein complexes at ER $\alpha$ target genes to activate transcription [31]. It is widely established that the diverse functions of E2 signaling depend on the differential recruitment of coregulators to the E2 bound ER $\alpha$ [32]. Although the molecular basis of ER $\alpha$ interactions with coregulators is well documented, very little is known regarding the mechanisms by which they influence the development and progression of BC. This review is focused on coregulator signaling in ER $\alpha$ driven BC.

\section{Coregulator functions in ER genomic actions}

Coregulators lack direct sequence-specific recruitment capabilities and their coregulator activity is dictated by NRs, such as ER $\alpha$, which attract them to the target gene loci. Recruitment of coregulator complexes to the nucleosome is a key step in transcriptional regulation [34]. Coactivator and corepressor complexes are recruited by ER through conserved nuclear receptor box (LxxLL, $\mathrm{L}$ is leucine, $\mathrm{x}$ is any amino acid) [35] and co-repressor nuclear receptor box (LxxH/IIxxxI/L, L is leucine, $\mathrm{H}$ is histidine, I is isoleucine, $\mathrm{X}$ is any amino acid) motifs [36], respectively. Coregulators facilitate ER $\alpha$-mediated transcription by providing diverse enzymatic activities required by the ER for appropriate chromatin modification to achieve optimal transcription [8,37] (Figure 2). ER $\alpha$ transcriptional outcomes are regulated by the dynamic interactions of histone acetyltransferases and histone deacetylases (HDACs), which are generally associated with coregulators [33]. Coactivators [steroid receptor coactivator (SRC) 1 and amplified in BC 1 (AIB1)] 
possess histone acetyltransferase activity, while corepressors [NR corepressor (NCOR) and metastasisassociated protein 1 (MTA1)] are associated with HDACs [38]. The ER $\alpha$ interactions with pioneer factors, coregulators, and post-translational modifiers will determine the E2-ER $\alpha$ transcriptional response [39]. Furthermore, BC progression is marked by coregulator-mediated chromatin remodeling and histone modifications [40]. For example, the coregulator, proline glutamic acid and leucine-rich protein 1 (PELP1) has a histone binding domain [41], recognizes histone modifications, and interacts with several chromatinmodifiers including lysine-specific histone demethylase (KDM) 1A [41], HDAC [42], protein arginine methyltransferases (PRMT) [43], and coactivator-associated arginine methyltransferase 1 (CARM1) [44]. Further, these large multiprotein complexes containing coactivators, ER $\alpha$, and transcriptional regulators assemble at ER $\alpha$ target genes in response to E2 binding to activate transcription [31]. Coregulators are also shown to play a critical role in estrogen-induced chromatin looping interactions during transcription at ER target genes [45]. Collectively, these findings suggest that coregulators are involved in many steps of ER $\alpha$ genomic actions including chromatin modification, remodeling, and transcription changes (Figure 2). Therefore, alterations in coregulators that commonly occur in $\mathrm{BC}$ may provide an advantage in enhancing the expression of $\mathrm{ER} \alpha$ target genes during $\mathrm{BC}$ progression.

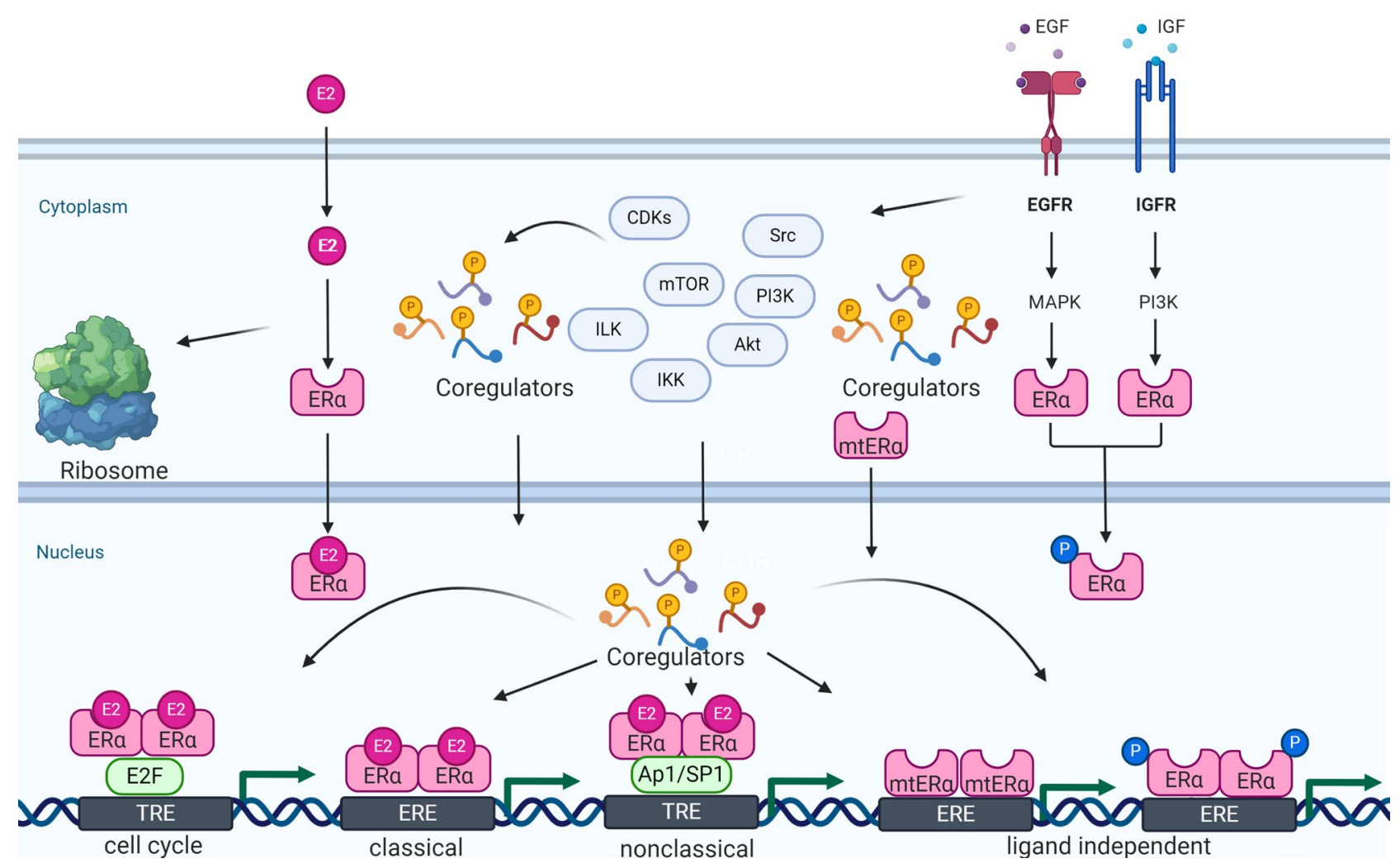

Figure 2. ER coregulator signaling mechanisms. ERa coregulators participate in multiple aspects of ER signaling including ER genomic (classical and non-classical), non-genomic, cell cycle, and ligand-independent signaling. In the cytoplasm, coregulators play a critical role in the activation of ER non-genomic signaling. Coregulators can be phosphorylated by cytosolic kinases and thus function as sensors of non-genomic signaling and integrate that signaling with ER genomic functions. Cell cyclin-dependent kinases (CDKs) also phosphorylate ER coregulators, and thus connect ER signaling to cell cycle progression. ER coregulators play an essential role in both classical and non-classical signaling via liganded ERa by promoting conducive chromatin remodeling. Deregulated growth factor signaling which commonly occurs in BC progression promotes post-translational modifications of ER and its coregulators; this facilitates ligand-independent activation of ERa target genes. Mutant ER (mtER) commonly occur in endocrine therapy resistant $\mathrm{BC}$ and mutations in the ligand binding domain of ERa create a constitutively active binding site for coregulators which promotes ligand-independent ER signaling. ILK: integrin-linked kinase; IKK: IkappaB kinase; mTOR: mechanistic target of rapamycin; EGF: epidermal growth factor; EGFR: EGF receptor; MAPK: mitogen-activated protein kinases; IGF: insulin-like growth factor; IGFR: IGF receptor; E2F: early 2 factor; TRE: trehalose; mtERa: mtER alpha

\section{Coregulator functions in ER non-genomic actions}

ER-non-genomic signaling is involved in rapid responses to E2 via activation of cytosolic kinases such as Src, MAPK, and PI3K [32] (Figure 2). ER $\alpha$ participates in non-genomic signaling via the formation of a multiprotein complex collectively called a "signalosome" [46]. Mechanistic studies showed that these 
complexes have several adaptor proteins (caveolins, striatin, p130Cas, Shc, etc.) and coregulator proteins such as SRC3, MTA1s, and PELP1 [47]. Using novel ligands that uniquely activate non-genomic signaling it was demonstrated that non-genomic pathways have distinct biological outcomes [48]. ER $\alpha$ extranuclear actions are also shown to play a role in cell motility/metastasis. PELP1 contributes to ER extranuclear actions leading to cell invasion by modulating the ER-Src-PELP1-ILK 1 (ILK1) pathway [49]. Cytoplasmic PELP1 signaling is shown to stimulate estrogen-related receptor $\gamma(\mathrm{ERR} \gamma)$ to promote cell survival [50]. E2-ER $\alpha$ signaling utilizes the PELP1-mediated PI3K/Akt signaling cascades to enhance matrix metalloproteinase-9 (MMP-9) expression in ER $\alpha+B C$ [51]. PELP1/AIB1-containing complexes in the cytoplasm function to promote advanced cancer phenotypes; including outgrowth of stem-like cells which are associated with E2-independent BC progression [52]. Furthermore, PELP1 has been documented to up-regulate pro-tumorigenic IKKe and thus enhance the migration of $\mathrm{BC}$ cells [53]. It was also demonstrated that PELP1 plays a critical role in the optimal activation of the mTOR, concomitantly, PELP1 deregulation contributes to excessive activation of mTOR signaling [54]. At the plasma membrane, E2 promotes ER $\alpha$ complex formation with HDAC6 and tubulin which contributes to the aggressiveness of ER-positive (ER+) BC cells [55]. In addition, E2-induces SRC-3 phosphorylation via direct interaction with $\mathrm{ER} \alpha$ in the cytoplasm; thus indicating it participates in early ER non-genomic actions [56]. The ER $\alpha$ corepressor, MTA1s, sequesters ER $\alpha$ in the cytoplasm, promoting non-genomic signaling, which has been shown to contribute to the malignant BC phenotype [57]. Overall, these findings suggest that coregulator proteins participate in ER $\alpha$ non-genomic actions by connecting ER with cytosolic kinases, and in some instances also by sequestering ER in the cytoplasm. Deregulation of $\mathrm{ER} \alpha$ coregulators can excessively activate non-genomic actions in BC cells which may have implications in endocrine therapy resistance.

\section{Coregulator functions in E2-ER $\alpha$ mediated cell cycle progression}

E2-ER $\alpha$ signaling promotes cell proliferation in a wide variety of tissues including the mammary gland [58, 59]. E2 participates in cell cycle progression by promoting activation of CDKs, the hyper-phosphorylation of retinoblastoma (pRb) in ER $\alpha+B C$ cells [59], and utilizing coregulator proteins such as PELP1 to couple E2-ER signaling to the cell cycle machinery. PELP1 is a unique substrate of CDKs and is necessary for E2 mediated progression through the cell cycle [60]. The ER coregulator SRC3 functions as a coactivator of E2F1 thus has the potential to drive cell proliferation of BC cells [61]. CARM1 another ER coregulator regulates E2-stimulated BC growth through up-regulation of E2F, however, E2 stimulation of cyclin D1 is CARM1 independent [62]. The single molecule real-time (SMRT) coregulator functions as a dual coactivator and corepressor for ER $\alpha$ and participates in E2-induced progression through the G1/S transition of the cell cycle [63]. Mediator subunit 1 (MED1) [dementia-related psychosis (DRP) 205/tripartite ATP-independent periplasmic (TRAP) 220/percutaneous balloon pericardiotomy (PBP)] interacts with ER using its NR LxxLL motif and plays a role in the optimal expression of ER-dependent genes such as E2F1 and cyclin D1 which are known to promote progression through the G1/S phase of the cell cycle [64]. Ribosome biogenesis is linked to cell growth and proliferation with E2 signaling positively regulating rRNA synthesis [65]. Interestingly, PELP1 plays a critical role in ribosomal biogenesis and is needed for active ribosomal RNA transcription [66]. The PELP1 and its associated proteins, testis-expressed protein 10 (TEX10) and WD repeat domain 18 (WDR18), are involved in large ribosomal subunit maturation [67]. Furthermore, PELP1 is required for the optimum synthesis of the $60 \mathrm{~S}$ ribosomal subunit [68]. Collectively, these findings suggest that coregulators play a critical role in driving E2-ER $\alpha$ cell cycle progression by promoting activation of cell cycle genes hence promoting ribosomal biogenesis (Figure 2).

\section{Coregulators in $\mathrm{BC}$ progression}

Sustained exposure to E2 increases the risk of BC [28]. Deregulation of several coregulators involved in estrogen action has been reported in $\mathrm{BC}$ progression [69]. Specifically, this deregulation can drive the growth and progression of endocrine therapy resistant BC. Approximately 400 coregulators have been identified that can interact with ER $\alpha$, and of those, approximately 100 coregulators are overexpressed in BC [70]. 
These alterations in the levels of coregulators enhance both ligand-independent, and ligand-dependent ER $\alpha$ signaling to drive growth and metastasis [69]. Recent studies utilizing next-generation sequencing of therapyresistant and metastatic $E R \alpha+B C$ have revealed that mutations in the ESR1 gene (ER $\alpha$ ) are frequent (30-40\%) and contribute to acquired endocrine resistant $\mathrm{BC}$ [71-73]. Importantly, even these mtERs must interact with their coregulators to mediate ER $\alpha$ signaling [30]. Many ER $\alpha$ coregulator proteins are present at rate-limiting levels. Changes in the level of expression and/or activity of coregulators can provide growth advantages by enhancing ER signaling [74]. Some coregulators have the potential to function as master regulators and oncogenes [43]. For example, SRC3 is overexpressed and/or amplified in breast tumors [75]. Overexpression of SRC3/AIB1 promoted tumorigenesis in transgenic mouse models [76], while SRC3 knockout mouse models showed resistance in the initiation of tumorigenesis by both carcinogens and oncogenes [77]. A transgenic mouse model engineered with mammary gland PELP1 overexpression demonstrated that PELP1 deregulation will contribute to carcinoma of the mammary gland [78]. BC susceptibility gene 1 (BRCA1) functions as an ER corepressor and its mutations are correlated with an increased risk of BC [79]. The up-regulation of ER $\alpha$ corepressor MTA1, is associated with increased invasiveness and metastatic potential of BC [80]. In addition, oncogenic PELP1 signaling is implicated in the progression of BC [81]. Furthermore, PELP1 expression is upregulated during BC progression [82-84]. Overall, these findings suggest deregulation of ER $\alpha$ coregulators commonly occurs during $\mathrm{BC}$ progression; and changes in expression or function of these coregulators have the potential to contribute to endocrine therapy resistance.

\section{Coregulators and endocrine therapy resistance}

Treatments for $\mathrm{ER} \alpha+\mathrm{BC}$ involve blocking ER signaling with antiestrogens (AE) or aromatase inhibitors (AI). The selective ER modulator (SERM), tamoxifen was approved to treat BC by the Food and Drug Administration (FDA) in 1978. In 1996, the FDA approved drug anastrozole, an AI, was first utilized to treat hormone sensitive BC. In 2002, fulvestrant, an AI and selective ER degrader (SERD) were approved in the US as a therapeutic for ER+, HER2- advanced BC. Unfortunately, the majority of BC patients will eventually develop resistance to therapy, with progression to incurable metastases $[85,86]$. While $\mathrm{AE} / \mathrm{AI}$ are initially effective, de novo and/or acquired therapy resistance is common. Importantly, therapy resistant BC tumors retain their ER signaling which is mediated by the interactions between activated ER $\alpha$ and critical coregulator proteins $[69,87]$.

Alterations in the coregulator expression or functions enable ER $\alpha$-signaling from AE-ER complexes, essentially converting the antagonist to an agonist [88, 89]. Approximately, 38\% of ESR1 coregulators identified in BC are over-expressed [87, 90, 91], such as SRC3 [92, 93], SRC2 [94], and PELP1 [95]. These deregulated coregulators contribute to BC progression [91], therapy resistance, and metastases [96-99]. The zeste homolog (EZH) 2-mediates epigenetic silencing of ER $\alpha$ cofactor growth regulation by estrogen in BC 1 (GREB1) contributes to the development of tamoxifen resistance [100]. As an adaptive response to endocrine therapy, tumors acquire mutations in the ER $\alpha$-LBD $[30,101,102]$. These $m t E R \alpha$ proteins have high constitutive transcriptional activity even in the absence of E2 [30,71]. The constitutive activity of these $m t E R \alpha$ proteins is strongly correlated with their ability to interact with coregulator proteins. Taken together, these data suggest that ESR1 mutations in the LBD maintain the ER $\alpha$-driven transcriptional program within these cancer cells, even in the absence of estrogenic ligand; thus contributing to endocrine resistance [30]. $\mathrm{ER} \alpha$ mutations are also associated with estrogen insensitivity by affecting the coupling between ligand binding and coactivator recruitment [103]. A recent proteomics-based study suggested differential coactivator recruitment such as SRC1, 2, or 3 may be partly responsible for the ability of mtER $\alpha$ proteins to drive metastatic BC [104]. mtER $\alpha$ recruits coactivators in the absence of hormone; effectively conferring anti-estrogen resistance by modulating the dynamics of the loop connecting Helix 11 and Helix 12, thus giving rise to an altered antagonist state that resists inhibition [29].

Coregulators are implicated in the differential actions of SERMs [105]. Downregulation of expression of the ER corepressor, NCOR1, is associated with tamoxifen resistance [106]. The MTA1s variant inhibits ER $\alpha$ genomic activity by sequestering ER $\alpha$ in the cytoplasm [57]. Furthermore, altered localization of PELP1 in 
the cytoplasm results in activation of PI3K [107]. In addition, PELP1-containing complexes contribute to the outgrowth of stem-like cells associated with E2-independent BC progression [52]. Timeless is another $\mathrm{ER} \alpha$ coactivator that promotes ER $\alpha$-induced gene regulation through one of its proximal NR LxxLL motifs, enhances ER $\alpha$ poly-ADP-ribosylation (PARylation), and is implicated with tamoxifen resistance [108]. Collectively, these published studies indicate that $\mathrm{ER} \alpha$ coregulator deregulation has the potential to promote ligand-independent ER $\alpha$ signaling. Therefore, targeting ER $\alpha$ coregulator functions could have potential therapeutic value in overcoming endocrine therapy resistance.

\section{Targeting coregulator functions in BC}

The contribution of multiple ER coregulators to endocrine therapy-resistant progression poses a therapeutic challenge, but also provides an opportunity for agents that specifically target oncogenic ER coregulators (Figure 3). Coregulators interact with ER via LxxLL motifs and blockage of these interactions may have therapeutic value. Early studies utilized LxxLL peptide-based approaches to target the ER-coregulator interface [109]. Progress in the area of LxxLL peptide-based inhibitors was recently reviewed by Skowron et al. [110]. A recent study used a cell-permeable stapled peptide, Arg4Lys1 (R4K1), to inhibit the $\mathrm{ER} \alpha /$ coactivator axis interactions [111]. However, translating bioactive peptides as a potential therapeutic has pharmacological limitations. Recently, using a peptidomimetic strategy, a small chemical molecule that functions as an ER coregulator binding modulator (ERX)-11, was developed. ERX-11 blocks the interaction between a subset of coregulators with ER $\alpha$. ERX-11 functions by blocking ER signaling and has also exhibited anti-proliferative activity against therapy-sensitive and therapy resistant human BC cells [112]. Furthermore, ERX-11 enhanced the efficacy of CDK4/6 inhibitor therapy and the combination of these two compounds may represent a viable therapeutic approach [113].

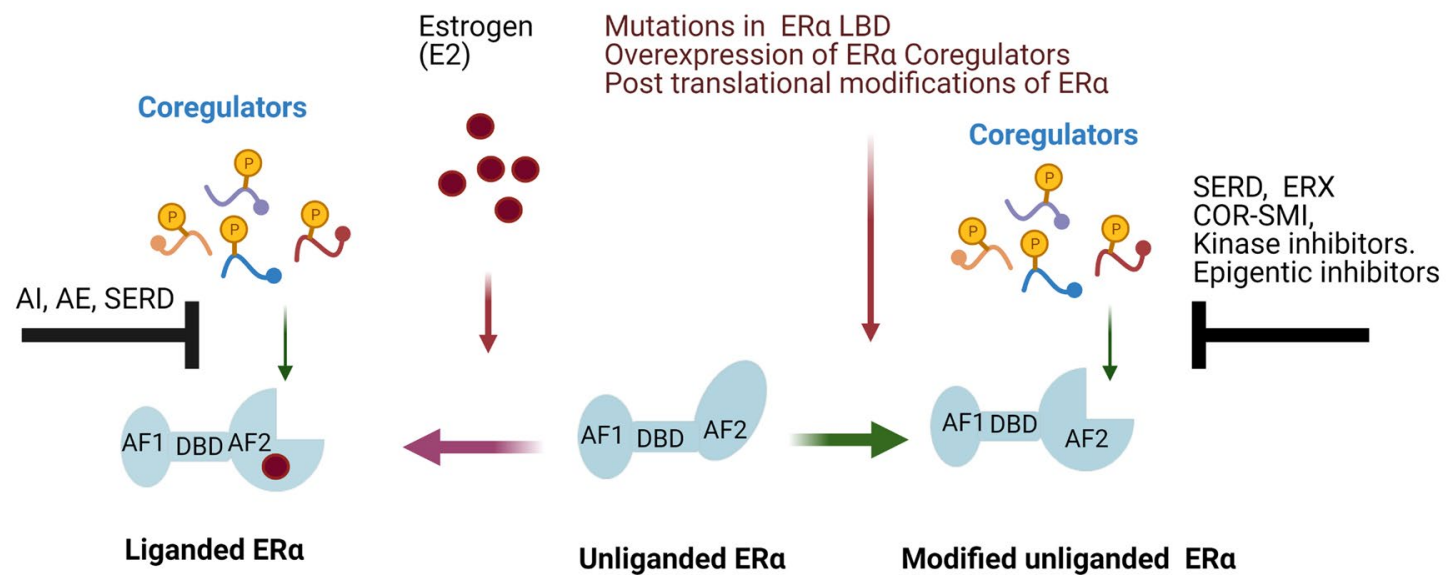

Figure 3. Approaches to target ERa-coregulator oncogenic signaling in BC. Ligand binding to the LBD of ERa facilitates coregulator recruitment and activation of ER $\alpha$ down-stream signaling. Ligand driven ERa-coregulator signaling can be targeted using Als (such as letrozole), AEs (such as tamoxifen), and SERDs (such as fulvestrant). Cytosolic signaling kinases such as Src, AKT, mTOR, and CDKs form complexes with ERa; and can phosphorylate ER and its coregulators leading to activation of ERa non-genomic signaling cascades. Therefore, targeting these kinases with pharmacological inhibitors will be useful in reducing ERa coregulator driven non-genomic signaling. Several pathological scenarios such as overexpression of ERa coregulators, epigenetic changes, post translational modifications, and mutations in ERa AF2 domain can facilitate ligand-independent ER signaling by recruiting coregulators. ERa signaling induced by oncogenic coregulators such as SRC1, SRC3, and PELP1 can be blocked by LxxLL motif blocking drugs called ERXs and SRC-3 small molecule inhibitor (SI-1) for SRC3 and inhibitors of epigenetic modifiers HDAC inhibitors (HDACi). Mutations in ERa create constitutive binding of coregulators to mtER and this signaling can be blocked by using ERXs or SMls, targeting coregulators, or by utilizing SERDs to degrade mtERa. COR: coregulator

Steroid receptor coactivators (SRC1, 2, and 3) are implicated in ER $\alpha$ signaling and BC progression. Recent studies identified the cardiac glycoside, bufalin, as a potent SMI for SRC1 and SRC3. Bufalin promoted SRC3 protein degradation and reduced tumor growth in mouse xenograft models of BC [114]. Using a cell-based functional assay for high-throughput screening, Song et al. [115] identified the SMI, SRC-3 inhibitor-2 (SI-2), for SRC3. SI-2 selectively degraded SRC3 in cells through direct physical interactions with SRC3, and induced $\mathrm{BC}$ cell death with low nanomolar half-limiting dose $\left(\mathrm{IC}_{50}\right)$ values, with no observed effects in the cell viability of normal cells. SI-2 represents a "first-in-class" drug that targets the oncogenic coactivator SRC3 and has 
great potential to treat advanced BC [115]. Screening for SRC SMIs also identified 4-Ethyl-2,6-bis-pyridin-3ylmethylene-cyclohexanone (MCB-613), which functions as a potent SRC small molecule "stimulator". This study found that MCB-613 selectively induced excessive stress in cancer cells implicating over-stimulation of the SRC coregulator signaling can be used as a potential strategy to kill cancer cells [116]. Unlike native [wild type (wt)] ER $\alpha, \mathrm{mtER} \alpha$ can bind to coregulators in the absence of ligand and contribute to endocrine therapy resistance by promoting ligand-independent ER $\alpha$ signaling. Therefore, SMIs targeting ER $\alpha$ coregulators could also be effective in targeting ligand-independent signaling by mtER $\alpha$.

Another means to block aberrant coregulator signaling is to target mtER $\alpha$ using SERDs $[117,118]$. Bazedoxifene (BZA), is a potent anti-estrogen that is shown to have improved inhibitory potency against mtER $\alpha$ compared to tamoxifen and also enhanced the efficacy of the CDK4/6 inhibitor, palbociclib [118]. Further, ER coregulators can contribute to ER crosstalk with endocrine signaling and metabolism which can alter downstream gene expression vital for tumor progression. Thus inhibitors targeting this axis will be useful in treating ER+ BC [119]. The mTOR axis is a critical component for PELP1 functions therefore, mTOR inhibitor(s) could be an agent for downregulating PELP1 oncogenic functions in BC [54]. Recent studies reported selective estrogen receptor covalent antagonist (H3B-5942), which can covalently inactivate both wt and mtER $\alpha$ by targeting cysteine (Cys) 530. H3B-5942 demonstrated significant activity as a monotherapy in xenograft models representing wtER $\alpha$ and $m t E R \alpha Y 537 \mathrm{~S} \mathrm{BC}$ and was superior to the treatment with SERD, fulvestrant. Additionally, H3B-5942 potency was improved in combination with either CDK4/6 inhibitors and/or mTOR inhibitors in both wtER $\alpha$ and $\mathrm{mtER} \alpha$ cell lines and/or tumor models [120].

Coregulator driven epigenetic changes are implicated in endocrine resistance. Since many coregulators have intrinsic and associated enzymatic activities, targeting these actions could represent another possible therapeutic strategy. HDACs inhibition has emerged as another potential strategy to overcome endocrine resistance especially in corepressor-deficient and tamoxifen-resistant BC [121]. The combination of the HDACi vorinostat and tamoxifen is well tolerated and exhibits encouraging activity in reversing hormone resistance. In addition, histone hyperacetylation is a useful pharmacodynamic marker for monitoring the efficacy of this combination therapy [122]. The ER coregulator PELP1 modulates epigenetic changes on ER target gene promoters via interactions with KDM 1, and KDM1 inhibitors are currently in clinical trials for other cancers [123]. KDM3A, a histone demethylase, is a positive regulator of ER activity and KDM3A deregulation contributes to endocrine therapy resistant disease [121]. EZH inhibitors have also been shown to overcome coregulator driven endocrine resistance in metastatic BC [100]. Considering the importance of coregulator signaling in $\mathrm{BC}$ progression and endocrine therapy resistance; SMIs that degrade coregulators, SMIs that interfere with coregulator binding to ER, or drugs that reverse coregulator driven epigenetic changes will have therapeutic value in treating endocrine therapy resistant BC.

\section{Conclusions}

During the past two decades, significant progress was made in understanding the molecular basis of ER $\alpha$ signaling. These studies revealed a critical role of coregulators in both ER $\alpha$ genomic and non-genomic signaling. Further, published studies established that coregulator proteins play an integral role in endocrine therapy resistance in BC. A significant number of advanced ER $\alpha$ has driven breast tumors to contain either the modification of ER $\alpha$ by mutations that enhance coregulator binding or altered expression and functions of coregulator proteins. Future studies dedicated to elucidating the molecular mechanisms of coregulator signaling that occur in endocrine therapy resistant tumors are clearly needed. Development of oral SERDs that uniquely degrade $m t E R \alpha$ or development of novel drugs that block mtER $\alpha$ interactions with coregulators will enable targeting of the ER $\alpha$-coregulator signaling. An enhanced understanding of ER coregulator signaling that occurs in tumors will facilitate developing new combination therapy options for BC using small molecule drugs that target ER $\alpha$-coregulator signaling.

\section{Abbreviations}

AE: antiestrogens

AF: activation of function 
AI: aromatase inhibitors

AIB1: amplified in breast cancer 1

BC: breast cancer

CARM1: coactivator-associated arginine methyltransferase 1

CDKs: cyclin-dependent kinases

E2: $17 \beta$-estradiol

E2F: early 2 factor

ER: estrogen receptor

ER+: ER-positive

EREs: estrogen response elements

ERX: estrogen receptor coregulator binding modulator

ER $\alpha$ : estrogen receptor alpha

$E R \alpha+$ : estrogen receptor alpha positive

ER $\beta$ : estrogen receptor beta

ESR: estrogen receptor

HDAC: histone deacetylase

HER2: human epidermal growth factor receptor-2

ILK: integrin-linked kinase

KDM: lysine-specific histone demethylase

LBD: ligand-binding domain

MAPK: mitogen-activated protein kinases

MTA1: metastasis-associated protein 1

mtER: mutant ER

mtERo: mutant ER alpha

mTOR: mechanistic target of rapamycin

NR: nuclear receptor

PELP1: proline glutamic acid and leucine-rich protein 1

PI3K: phosphatidylinositol 3-kinase

PR: progesterone receptor

SERD: selective estrogen receptor degrader

SMIs: small molecule inhibitors

SRC: steroid receptor coactivator

TNBC: triple-negative breast cancer

TRE: trehalose

wt: wild type

\section{Declarations}

Author contributions

KAA and RKV conceived the idea, designed, wrote, and edited the review.

\section{Conflicts of interest}

The authors declare that they have no conflicts of interest. 


\section{Ethical approval}

Not applicable.

\section{Consent to participate}

Not applicable.

\section{Consent to publication}

Not applicable.

\section{Availability of data and materials}

Not applicable.

\section{Funding}

This work is supported in part by NIH grants (RV); NIH F31 Fellowship 1F31CA257298 (KA). The funders had no role in study design, data collection and analysis, decision to publish, or preparation of the manuscript.

\section{Copyright}

(C) The Author(s) 2021.

\section{References}

1. Sung H, Ferlay J, Siegel RL, Laversanne M, Soerjomataram I, Jemal A, et al. Global cancer statistics 2020: globocan estimates of incidence and mortality worldwide for 36 cancers in 185 countries. CA Cancer J Clin. 2021;71:209-49.

2. Polyak K. Breast cancer: origins and evolution. J Clin Invest. 2007;117:3155-63.

3. Fragomeni SM, Sciallis A, Jeruss JS. Molecular subtypes and local-regional control of breast cancer. Surg Oncol Clin N Am. 2018;27:95-120.

4. Calle EE, Kaaks R. Overweight, obesity and cancer: epidemiological evidence and proposed mechanisms. Nat Rev Cancer. 2004;4:579-91.

5. Lehmann BD, Bauer JA, Chen X, Sanders ME, Chakravarthy AB, Shyr Y, et al. Identification of human triple-negative breast cancer subtypes and preclinical models for selection of targeted therapies. J Clin Invest. 2011;121:2750-67.

6. Masuda H, Baggerly KA, Wang Y, Zhang Y, Gonzalez-Angulo AM, Meric-Bernstam F, et al. Differential response to neoadjuvant chemotherapy among 7 triple-negative breast cancer molecular subtypes. Clin Cancer Res. 2013;19:5533-40.

7. Bianchini G, Balko JM, Mayer IA, Sanders ME, Gianni L. Triple-negative breast cancer: challenges and opportunities of a heterogeneous disease. Nat Rev Clin Oncol. 2016;13:674-90.

8. McDonnell DP, Norris JD. Connections and regulation of the human estrogen receptor. Science. 2002;296:1642-4

9. Bafna D, Ban F, Rennie PS, Singh K, Cherkasov A. Computer-aided ligand discovery for estrogen receptor alpha. Int J Mol Sci. 2020;21:4193.

10. Jensen EV, Desombre ER, Kawashima T, Suzuki T, Kyser K, Jungblut PW. Estrogen-binding substances of target tissues. Science. 1967;158:529-30.

11. Jensen EV, Suzuki T, Kawashima T, Stumpf WE, Jungblut PW, DeSombre ER. A two-step mechanism for the interaction of estradiol with rat uterus. Proc Natl Acad Sci U S A. 1968;59:632-8.

12. Paech K, Webb P, Kuiper GG, Nilsson S, Gustafsson J, Kushner PJ, et al. Differential ligand activation of estrogen receptors ERalpha and ERbeta at AP1 sites. Science. 1997;277:1508-10.

13. Speirs V, Malone C, Walton DS, Kerin MJ, Atkin SL. Increased expression of estrogen receptor beta mRNA in tamoxifen-resistant breast cancer patients. Cancer Res. 1999;59:5421-4. 
14. Shaaban AM, Green AR, Karthik S, Alizadeh Y, Hughes TA, Harkins L, et al. Nuclear and cytoplasmic expression of ERbeta1, ERbeta2, and ERbeta5 identifies distinct prognostic outcome for breast cancer patients. Clin Cancer Res. 2008;14:5228-35.

15. Siersbæk R, Kumar S, Carroll JS. Signaling pathways and steroid receptors modulating estrogen receptor alpha function in breast cancer. Genes Dev. 2018;32:1141-54.

16. Ponglikitmongkol M, Green S, Chambon P. Genomic organization of the human oestrogen receptor gene. EMBO J. 1988; 7:3385-8.

17. Bocchinfuso WP, Korach KS. Mammary gland development and tumorigenesis in estrogen receptor knockout mice. J Mammary Gland Biol Neoplasia. 1997;2:323-34.

18. Thomas C, Gustafsson JA. The different roles of ER subtypes in cancer biology and therapy. Nat Rev Cancer. 2011;11:597-608.

19. Gustafsson JA, Warner M. Estrogen receptor beta in the breast: role in estrogen responsiveness and development of breast cancer. J Steroid Biochem Mol Biol. 2000;74:245-8.

20. Zhou Y, Liu X. The role of estrogen receptor beta in breast cancer. Biomark Res. 2020;8:39.

21. Sellitto A, D’Agostino Y, Alexandrova E, Lamberti J, Pecoraro G, Memoli D, et al. Insights into the role of estrogen receptor beta in triple-negative breast cancer. Cancers (Basel). 2020;12:1477.

22. Brzozowski AM, Pike AC, Dauter Z, Hubbard RE, Bonn T, Engström O, et al. Molecular basis of agonism and antagonism in the oestrogen receptor. Nature. 1997;389:753-8.

23. Björnström L, Sjöberg M. Mechanisms of estrogen receptor signaling: convergence of genomic and nongenomic actions on target genes. Mol Endocrinol. 2005;19:833-42.

24. Mason CE, Shu FJ, Wang C, Session RM, Kallen RG, Sidell N, et al. Location analysis for the estrogen receptor-alpha reveals binding to diverse ERE sequences and widespread binding within repetitive DNA elements. Nucleic Acids Res. 2010;38:2355-68.

25. Losel R, Wehling M. Nongenomic actions of steroid hormones. Nat Rev Mol Cell Biol. 2003;4:46-56.

26. Migliaccio A, Di Domenico M, Castoria G, de Falco A, Bontempo P, Nola E, et al. Tyrosine kinase/p21ras/ MAP-kinase pathway activation by estradiol-receptor complex in MCF-7 cells. EMBO J.1996;15:1292-300.

27. Atanaskova N, Keshamouni VG, Krueger JS, Schwartz JA, Miller F, Reddy KB. MAP kinase/estrogen receptor cross-talk enhances estrogen-mediated signaling and tumor growth but does not confer tamoxifen resistance. Oncogene. 2002;21:4000-8.

28. Anbalagan M, Rowan BG. Estrogen receptor alpha phosphorylation and its functional impact in human breast cancer. Mol Cell Endocrinol. 2015;418:264-72.

29. Fanning SW, Mayne CG, Dharmarajan V, Carlson KE, Martin TA, Novick SJ, et al. Estrogen receptor alpha somatic mutations Y537S and D538G confer breast cancer endocrine resistance by stabilizing the activating function-2 binding conformation. Elife. 2016;5:e12792.

30. Jeselsohn R, Buchwalter G, De Angelis C, Brown M, Schiff R. ESR1 mutations-a mechanism for acquired endocrine resistance in breast cancer. Nat Rev Clin Oncol. 2015;12:573-83.

31. McKenna NJ, Lanz RB, O'Malley BW. Nuclear receptor coregulators: cellular and molecular biology. Endocr Rev. 1999;20:321-44.

32. Hall JM, McDonnell DP. Coregulators in nuclear estrogen receptor action: from concept to therapeutic targeting. Mol Interv. 2005;5:343-57.

33. Torchia J, Glass C, Rosenfeld MG. Co-activators and co-repressors in the integration of transcriptional responses. Curr Opin Cell Biol. 1998;10:373-83.

34. Millard CJ, Watson PJ, Fairall L, Schwabe JW. An evolving understanding of nuclear receptor coregulator proteins. J Mol Endocrinol. 2013;51:T23-36.

35. Heery DM, Kalkhoven E, Hoare S, Parker MG. A signature motif in transcriptional co-activators mediates binding to nuclear receptors. Nature. 1997;387:733-6. 
36. Hu X, Lazar MA. The CoRNR motif controls the recruitment of corepressors by nuclear hormone receptors. Nature. 1999;402:93-6.

37. Rosenfeld MG, Lunyak VV, Glass CK. Sensors and signals: a coactivator/corepressor/epigenetic code for integrating signal-dependent programs of transcriptional response. Genes Dev. 2006;20:1405-28.

38. Tsai MJ, O'Malley BW. Molecular mechanisms of action of steroid/thyroid receptor superfamily members. Annu Rev Biochem. 1994;63:451-86.

39. Vasquez YM. Estrogen-regulated transcription: mammary gland and uterus. Steroids. 2018;133:82-6.

40. Sukocheva OA, Lukina E, Friedemann M, Menschikowski M, Hagelgans A, Aliev G. The crucial role of epigenetic regulation in breast cancer anti-estrogen resistance: current findings and future perspectives. Semin Cancer Biol. 2020; [Epub ahead of print].

41. Nair SS, Nair BC, Cortez V, Chakravarty D, Metzger E, Schüle R, et al. PELP1 is a reader of histone H3 methylation that facilitates oestrogen receptor-alpha target gene activation by regulating lysine demethylase 1 specificity. EMBO Rep. 2010;11:438-44.

42. Roy SS, Gonugunta VK, Bandyopadhyay A, Rao MK, Goodall GJ, Sun LZ, et al. Significance of PELP1/ HDAC2/miR-200 regulatory network in EMT and metastasis of breast cancer. Oncogene. 2014; 33:3707-16.

43. Mann M, Zou Y, Chen Y, Brann D, Vadlamudi R. PELP1 oncogenic functions involve alternative splicing via PRMT6. Mol Oncol. 2014;8:389-400.

44. Mann M, Cortez V, Vadlamudi R. PELP1 oncogenic functions involve CARM1 regulation. Carcinogenesis. 2013;34:1468-75.

45. Panigrahi AK, Foulds CE, Lanz RB, Hamilton RA, Yi P, Lonard DM, et al. SRC-3 coactivator governs dynamic estrogen-induced chromatin looping interactions during transcription. Mol Cell. 2018;70:679-94.e7.

46. Levin ER. Integration of the extranuclear and nuclear actions of estrogen. Mol Endocrinol. 2005; 19:1951-9.

47. Acconcia F, Kumar R. Signaling regulation of genomic and nongenomic functions of estrogen receptors. Cancer Lett. 2006;238:1-14.

48. Harrington WR, Kim SH, Funk CC, Madak-Erdogan Z, Schiff R, Katzenellenbogen JA, et al. Estrogen dendrimer conjugates that preferentially activate extranuclear, nongenomic versus genomic pathways of estrogen action. Mol Endocrinol. 2006;20:491-502.

49. Chakravarty D, Nair SS, Santhamma B, Nair BC, Wang L, Bandyopadhyay A, et al. Extranuclear functions of ER impact invasive migration and metastasis by breast cancer cells. Cancer Res. 2010;70:4092-101.

50. Girard BJ, Regan Anderson TM, Welch SL, Nicely J, Seewaldt VL, Ostrander JH. Cytoplasmic PELP1 and ERRgamma protect human mammary epithelial cells from Tam-induced cell death. PLoS One. 2015;10:e0121206.

51. Pan Y, Wang X, Zhang Y, Qiao J, Sasano H, McNamara K, et al. Estradiol-induced MMP-9 expression via PELP1-mediated membrane-initiated signaling in ERalpha-positive breast cancer cells. Horm Cancer. 2020;11:87-96.

52. Truong TH, Hu H, Temiz NA, Hagen KM, Girard BJ, Brady NJ, et al. Cancer stem cell phenotypes in ER+ breast cancer models are promoted by PELP1/AIB1 complexes. Mol Cancer Res. 2018;16:707-19.

53. Girard BJ, Knutson TP, Kuker B, McDowell L, Schwertfeger KL, Ostrander JH. Cytoplasmic localization of proline, glutamic acid, leucine-rich protein 1 (PELP1) induces breast epithelial cell migration through up-regulation of inhibitor of kappaB kinase and inflammatory cross-talk with macrophages. J Biol Chem. 2017;292:339-50.

54. Gonugunta VK, Sareddy GR, Krishnan SR, Cortez V, Roy SS, Tekmal RR, et al. Inhibition of mTOR signaling reduces PELP1-mediated tumor growth and therapy resistance. Mol Cancer Ther. 2014;13:1578-88. 
55. Azuma K, Urano T, Horie-Inoue K, Hayashi S, Sakai R, Ouchi Y, et al. Association of estrogen receptor alpha and histone deacetylase 6 causes rapid deacetylation of tubulin in breast cancer cells. Cancer Res. 2009;69:2935-40.

56. Zheng FF, Wu RC, Smith CL, O'Malley BW. Rapid estrogen-induced phosphorylation of the SRC-3 coactivator occurs in an extranuclear complex containing estrogen receptor. Mol Cell Biol. 2005;25:8273-84.

57. Kumar R, Wang RA, Mazumdar A, Talukder AH, Mandal M, Yang Z, et al. A naturally occurring MTA1 variant sequesters oestrogen receptor-alpha in the cytoplasm. Nature. 2002;418:654-7.

58. Foster JS, Henley DC, Ahamed S, Wimalasena J. Estrogens and cell-cycle regulation in breast cancer. Trends Endocrinol Metab. 2001;12:320-7.

59. Foster JS, Henley DC, Bukovsky A, Seth P, Wimalasena J. Multifaceted regulation of cell cycle progression by estrogen: regulation of Cdk inhibitors and Cdc25A independent of cyclin D1-Cdk4 function. Mol Cell Biol. 2001;21:794-810.

60. Nair BC, Nair SS, Chakravarty D, Challa R, Manavathi B, Yew PR, et al. Cyclin-dependent kinase-mediated phosphorylation plays a critical role in the oncogenic functions of PELP1. Cancer Res. 2010;70:7166-75.

61. Louie MC, Zou JX, Rabinovich A, Chen HW. ACTR/AIB1 functions as an E2F1 coactivator to promote breast cancer cell proliferation and antiestrogen resistance. Mol Cell Biol. 2004;24:5157-71.

62. Frietze S, Lupien M, Silver PA, Brown M. CARM1 regulates estrogen-stimulated breast cancer growth through up-regulation of E2F1. Cancer Res. 2008;68:301-6.

63. Blackmore JK, Karmakar S, Gu G, Chaubal V, Wang L, Li W, et al. The SMRT coregulator enhances growth of estrogen receptor-alpha-positive breast cancer cells by promotion of cell cycle progression and inhibition of apoptosis. Endocrinology. 2014;155:3251-61.

64. Jiang P, Hu Q, Ito M, Meyer S, Waltz S, Khan S, et al. Key roles for MED1 LxxLL motifs in pubertal mammary gland development and luminal-cell differentiation. Proc Natl Acad Sci U S A. 2010;107:6765-70.

65. Ray S, Johnston R, Campbell DC, Nugent S, McDade SS, Waugh D, et al. Androgens and estrogens stimulate ribosome biogenesis in prostate and breast cancer cells in receptor dependent manner. Gene. 2013;526:46-53.

66. Gonugunta VK, Nair BC, Rajhans R, Sareddy GR, Nair SS, Vadlamudi RK. Regulation of rDNA transcription by proto-oncogene PELP1. PLoS One. 2011;6:e21095.

67. Finkbeiner E, Haindl M, Raman N, Muller S. SUMO routes ribosome maturation. Nucleus. 2011;2:527-32.

68. Castle CD, Cassimere EK, Denicourt C. LAS1L interacts with the mammalian Rix1 complex to regulate ribosome biogenesis. Mol Biol Cell. 2012;23:716-28.

69. Dasgupta S, O'Malley BW. Transcriptional coregulators: emerging roles of SRC family of coactivators in disease pathology. J Mol Endocrinol. 2014;53:R47-59.

70. Dasgupta S, Lonard DM, O'Malley BW. Nuclear receptor coactivators: master regulators of human health and disease. Annu Rev Med. 2014;65:279-92.

71. Toy W, Weir H, Razavi P, Lawson M, Goeppert AU, Mazzola AM, et al. Activating ESR1 mutations differentially affect the efficacy of ER antagonists. Cancer Discov. 2017;7:277-87.

72. Jeselsohn R, De Angelis C, Brown M, Schiff R. The evolving role of the estrogen receptor mutations in endocrine therapy-resistant breast cancer. Curr Oncol Rep. 2017;19:35.

73. Oesterreich S, Davidson NE. The search for ESR1 mutations in breast cancer. Nat Genet. 2013;45:1415-6.

74. O’Malley BW. Molecular biology. Little molecules with big goals. Science. 2006;313:1749-50.

75. Anzick SL, Kononen J, Walker RL, Azorsa DO, Tanner MM, Guan XY, et al. AIB1, a steroid receptor coactivator amplified in breast and ovarian cancer. Science. 1997;277:965-8.

76. Torres-Arzayus MI, Font de Mora J, Yuan J, Vazquez F, Bronson R, Rue M, et al. High tumor incidence and activation of the PI3K/AKT pathway in transgenic mice define AIB1 as an oncogene. Cancer Cell. 2004;6:263-74. 
77. Kuang SQ, Liao L, Wang S, Medina D, O'Malley BW, Xu J. Mice lacking the amplified in breast cancer 1/ steroid receptor coactivator-3 are resistant to chemical carcinogen-induced mammary tumorigenesis. Cancer Res. 2005;65:7993-8002.

78. Cortez V, Samayoa C, Zamora A, Martinez L, Tekmal RR, Vadlamudi RK. PELP1 overexpression in the mouse mammary gland results in the development of hyperplasia and carcinoma. Cancer Res. 2014;74:7395-405.

79. Martin AM, Weber BL. Genetic and hormonal risk factors in breast cancer. J Natl Cancer Inst. 2000;92:1126-35.

80. Nicolson GL, Nawa A, Toh Y, Taniguchi S, Nishimori K, Moustafa A. Tumor metastasis-associated human MTA1 gene and its MTA1 protein product: role in epithelial cancer cell invasion, proliferation and nuclear regulation. Clin Exp Metastasis. 2003;20:19-24.

81. Vadlamudi RK, Wang RA, Mazumdar A, Kim Y, Shin J, Sahin A, et al. Molecular cloning and characterization of PELP1, a novel human coregulator of estrogen receptor alpha. J Biol Chem. 2001;276:38272-9.

82. Ravindranathan P, Lange CA, Raj GV. Minireview: deciphering the cellular functions of PELP1. Mol Endocrinol. 2015;29:1222-9.

83. Rajhans R, Nair S, Holden AH, Kumar R, Tekmal RR, Vadlamudi RK. Oncogenic potential of the nuclear receptor coregulator proline-, glutamic acid-, leucine-rich protein 1 /modulator of the nongenomic actions of the estrogen receptor. Cancer Res. 2007;67:5505-12.

84. Flågeng MH, Knappskog S, Gjerde J, Lønning PE, Mellgren G. Estrogens correlate with PELP1 expression in ER positive breast cancer. PLoS One. 2015;10:e0134351.

85. Turner NC, Neven P, Loibl S, Andre F. Advances in the treatment of advanced oestrogen-receptor-positive breast cancer. Lancet. 2016;389:2403-14.

86. Musgrove EA, Sutherland RL. Biological determinants of endocrine resistance in breast cancer. Nat Rev Cancer. 2009;9:631-43.

87. Lonard DM, Lanz RB, O'Malley BW. Nuclear receptor coregulators and human disease. Endocr Rev. 2007;28:575-87.

88. O'Hara J, Vareslija D, McBryan J, Bane F, Tibbitts P, Byrne C, et al. AIB1: ERalpha transcriptional activity is selectively enhanced in aromatase inhibitor-resistant breast cancer cells. Clin Cancer Res. 2012;18:3305-15.

89. Kurebayashi J. Endocrine-resistant breast cancer: underlying mechanisms and strategies for overcoming resistance. Breast Cancer. 2003;10:112-9.

90. Lonard DM, O'Malley BW. Nuclear receptor coregulators: modulators of pathology and therapeutic targets. Nat Rev Endocrinol. 2012;8:598-604.

91. Liu J, Liu Z, Li M, Tang W, Pratap UP, Luo Y, et al. Interaction of transcription factor AP-2 gamma with protooncogene PELP1 promotes tumorigenesis by enhancing RET signaling. Mol Oncol. 2021;15:1146-61.

92. List HJ, Reiter R, Singh B, Wellstein A, Riegel AT. Expression of the nuclear coactivator AIB1 in normal and malignant breast tissue. Breast Cancer Res Treat. 2001;68:21-8.

93. Azorsa DO, Cunliffe HE, Meltzer PS. Association of steroid receptor coactivator AIB1 with estrogen receptor-alpha in breast cancer cells. Breast Cancer Res Treat. 2001;70:89-101.

94. Kurebayashi J, Otsuki T, Kunisue H, Tanaka K, Yamamoto S, Sonoo H. Expression levels of estrogen receptor-alpha, estrogen receptor-beta, coactivators, and corepressors in breast cancer. Clin Cancer Res. 2000;6:512-8.

95. Habashy HO, Powe DG, Rakha EA, Ball G, Macmillan RD, Green AR, et al. The prognostic significance of PELP1 expression in invasive breast cancer with emphasis on the ER-positive luminal-like subtype. Breast Cancer Res Treat. 2010;120:603-12. 
96. Kumar R, Zhang H, Holm C, Vadlamudi RK, Landberg G, Rayala SK. Extranuclear coactivator signaling confers insensitivity to tamoxifen. Clin Cancer Res. 2009;15:4123-30.

97. Shou J, Massarweh S, Osborne CK, Wakeling AE, Ali S, Weiss $\mathrm{H}$, et al. Mechanisms of tamoxifen resistance: increased estrogen receptor-HER2/neu cross-talk in ER/HER2-positive breast cancer. J Natl Cancer Inst. 2004;96:926-35.

98. Burandt E, Jens G, Holst F, Jänicke F, Müller V, Quaas A, et al. Prognostic relevance of AIB1 (NCoA3) amplification and overexpression in breast cancer. Breast Cancer Res Treat. 2013;137:745-53.

99. Girard BJ, Daniel AR, Lange CA, Ostrander JH. PELP1: a review of PELP1 interactions, signaling, and biology. Mol Cell Endocrinol. 2014;382:642-51.

100. Wu Y, Zhang Z, Cenciarini ME, Proietti CJ, Amasino M, Hong T, et al. Tamoxifen resistance in breast cancer is regulated by the EZH2-ERalpha-GREB1 transcriptional axis. Cancer Res. 2018;78:671-84.

101. Yang J, Wei X, Tufan T, Kuscu C, Unlu H, Farooq S, et al. Recurrent mutations at estrogen receptor binding sites alter chromatin topology and distal gene expression in breast cancer. Genome Biol. 2018;19:190.

102. Langdon SP. Estrogen receptor signaling in cancer. Cancers. 2020;12:2744.

103. Li Y, Coons LA, Houtman R, Carlson KE, Martin TA, Mayne CG, et al. A mutant form of ERalpha associated with estrogen insensitivity affects the coupling between ligand binding and coactivator recruitment. Sci Signal. 2020;13:eaaw4653.

104. Gates LA, Gu G, Chen Y, Rohira AD, Lei JT, Hamilton RA, et al. Proteomic profiling identifies key coactivators utilized by mutant ERalpha proteins as potential new therapeutic targets. Oncogene. 2018;37:4581-98.

105. Shang Y, Brown M. Molecular determinants for the tissue specificity of SERMs. Science. 2002;295:2465-8.

106. Girault I, Lerebours F, Amarir S, Tozlu S, Tubiana-Hulin M, Lidereau R, et al. Expression analysis of estrogen receptor alpha coregulators in breast carcinoma: evidence that NCOR1 expression is predictive of the response to tamoxifen. Clin Cancer Res. 2003;9:1259-66.

107. Vadlamudi RK, Manavathi B, Balasenthil S, Nair SS, Yang Z, Sahin AA, et al. Functional implications of altered subcellular localization of PELP1 in breast cancer cells. Cancer Res. 2005;65:7724-32.

108. Magne Nde CB, Casas Gimeno G, Docanto M, Knower KC, Young MJ, Buehn J, et al. Timeless is a novel estrogen receptor co-activator involved in multiple signaling pathways in MCF-7 Cells. J Mol Biol. 2018;430:1531-43.

109. Norris JD, Paige LA, Christensen DJ, Chang CY, Huacani MR, Fan D, et al. Peptide antagonists of the human estrogen receptor. Science. 1999;285:744-6.

110. Skowron KJ, Booker K, Cheng C, Creed S, David BP, Lazzara PR, et al. Steroid receptor/coactivator binding inhibitors: an update. Mol Cell Endocrinol. 2019;493:110471.

111. Speltz TE, Danes JM, Stender JD, Frasor J, Moore TW. A cell-permeable stapled peptide inhibitor of the estrogen receptor/coactivator interaction. ACS Chem Biol. 2018;13:676-84.

112. Raj GV, Sareddy GR, Ma S, Lee TK, Viswanadhapalli S, Li R, et al. Estrogen receptor coregulator binding modulators (ERXs) effectively target estrogen receptor positive human breast cancers. Elife. 2017;6:e26857.

113. Viswanadhapalli S, Ma S, Sareddy GR, Lee TK, Li M, Gilbreath C, et al. Estrogen receptor coregulator binding modulator (ERX-11) enhances the activity of CDK4/6 inhibitors against estrogen receptorpositive breast cancers. Breast Cancer Res. 2019;21:150.

114. Wang Y, Lonard DM, Yu Y, Chow DC, Palzkill TG, Wang J, et al. Bufalin is a potent small-molecule inhibitor of the steroid receptor coactivators SRC-3 and SRC-1. Cancer Res. 2014;74:1506-17.

115. Song X, Chen J, Zhao M, Zhang C, Yu Y, Lonard DM, et al. Development of potent small-molecule inhibitors to drug the undruggable steroid receptor coactivator-3. Proc Natl Acad Sci U S A. 2016;113:4970-5. 
116. Wang L, Yu Y, Chow DC, Yan F, Hsu CC, Stossi F, et al. Characterization of a steroid receptor coactivator small molecule stimulator that overstimulates cancer cells and leads to cell stress and death. Cancer Cell. 2015;28:240-52.

117. Weir HM, Bradbury RH, Lawson M, Rabow AA, Buttar D, Callis RJ, et al. AZD9496: an oral estrogen receptor inhibitor that blocks the growth of ER-positive and ESR1-mutant breast tumors in preclinical models. Cancer Res. 2016;76:3307-18.

118. Fanning SW, Jeselsohn R, Dharmarajan V, Mayne CG, Karimi M, Buchwalter G, et al. The SERM/SERD bazedoxifene disrupts ESR1 helix 12 to overcome acquired hormone resistance in breast cancer cells. Elife. 2018;7:e37161.

119. Blundon MA, Dasgupta S. Metabolic dysregulation controls endocrine therapy-resistant cancer recurrence and metastasis. Endocrinology. 2019;160:1811-20.

120. Puyang X, Furman C, Zheng GZ, Wu ZJ, Banka D, Aithal K, et al. Discovery of selective estrogen receptor covalent antagonists for the treatment of ERalpha(WT) and ERalpha(MUT) breast cancer. Cancer Discov. 2018;8:1176-93.

121. Wade MA, Jones D, Wilson L, Stockley J, Coffey K, Robson CN, et al. The histone demethylase enzyme KDM3A is a key estrogen receptor regulator in breast cancer. Nucleic Acids Res. 2015;43:196-207.

122. Munster PN, Thurn KT, Thomas S, Raha P, Lacevic M, Miller A, et al. A phase II study of the histone deacetylase inhibitor vorinostat combined with tamoxifen for the treatment of patients with hormone therapy-resistant breast cancer. Br J Cancer. 2011;104:1828-35.

123. Cortez V, Mann M, Tekmal S, Suzuki T, Miyata N, Rodriguez-Aguayo C, et al. Targeting the PELP1-KDM1 axis as a potential therapeutic strategy for breast cancer. Breast Cancer Res. 2012;14:R108. 